\title{
Simulation and Performance Analysis of
}

\section{Passive Optical Networks (PONs)}

\author{
Mostafa Ghathor, Ayman M. Mokhtar, and Samy S. Ghoniemy \\ Military Technical College
}

\begin{abstract}
$\underline{\text { Abstract: }}$
This paper aims to explain the design and planning of a passive optical networks (PON) which can build a fictitious environment allowing to study fiber to the home (FTTH) networks in depth and decide the optimal option for this environment. We design a network architecture based on FTTH systems with different bit rates $(1.25 \mathrm{~GB} / \mathrm{s}, 2 \mathrm{~GB} / \mathrm{s}, 2.5 \mathrm{~Gb} / \mathrm{s}, 5 \mathrm{~Gb} / \mathrm{s}$ and $10 \mathrm{~GB} / \mathrm{s})$. This architecture is targeted to deliver a very high speed data using optical communication between the edge nodes connecting the end users. This transmission allows the simultaneous delivery of triple play service (data, voice and video). In our design various data rates are studied. It has been observed that the proposed system is one of the most suitable methods concerning data rate. It is demonstrated that as we increase the data rate, the number of accommodated user's decreases due to high bit error rate. Also by increasing the distance of transmission, the system will be undesirable due to increasing the bit error rate.
\end{abstract}

\section{Introduction:}

Fiber access network technologies are good candidate for the future communication era, it can cope the increasing demand for high-speed communication, video, high definition multimedia applications, on-line interaction, and peer-to-peer file transfer. These requirements pursued the development of optical access technologies. FTTx is a generic term for various optical fiber delivery topologies that are categorized according to where the fiber terminates. Passive optical network (PON) is a point-tomultipoint fiber network architecture in which unpowered optical splitters are used to take one input and splits it to broadcast signals to many users. PON based FTTx is a promising solution that can break through the economic barrier of traditional point-to-point solutions. Once fibers are deployed with PON based FTTH solutions 
the challenge becomes how to exploit the huge available bandwidth of the optical fibers. Network architecture based on PON technologies is elaborated along with options for different multiple access techniques. Several competing PON concepts have been developed, such as the Asynchronous Transfer Mode PON (APON) which uses ATM encapsulation of transported data. APON was followed by the Broadband PON (BPON). Gigabit Passive Optical Network (GPON) has enhanced capability comparing with APON and BPON.

\section{PON Technologies:}

\section{2-a. PON:}

A Passive Optical Network (PON) is a point-to-multipoint optical access network with no active elements in the signal path from source to destination. Here, all transmissions are performed between an optical line terminal (OLT) and optical network units (ONUs) mainly through an optical splitter / combiner. The OLT resides in the central office ( $\mathrm{CO}$ ) and connects the optical access network to the metropolitan area network (MAN) or wide-area network (WAN). On the other hand, each ONU is usually located at either the curb (FTTC) or the end-user location (FTTB) and fiber-to-the-home (FTTH), and deliver broadband voice, data, and video services to subscribers. Hence, PON saves costs, power supply, equipment distribution and more optimal and efficient utilization of the fiber optical infrastructure [1].

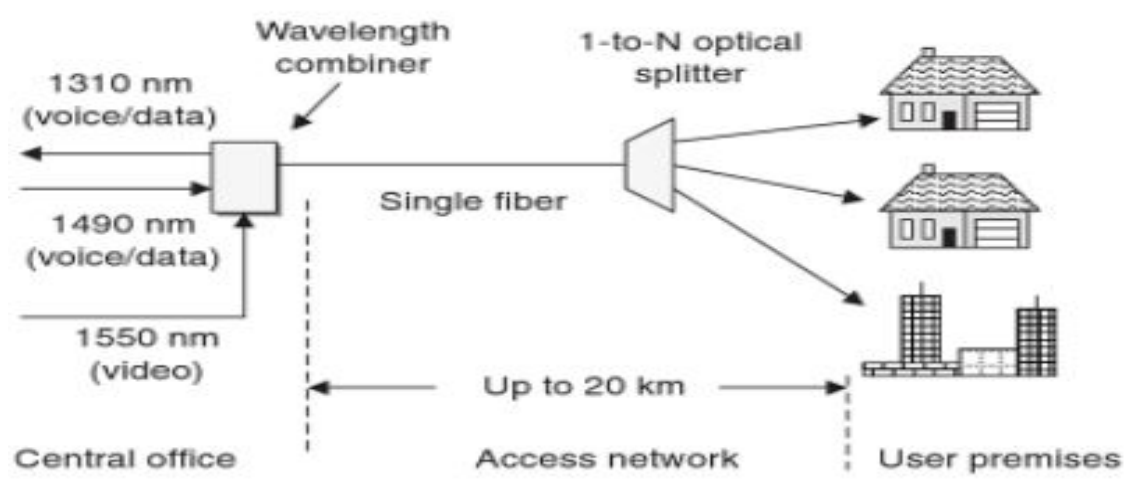

Fig. 1 Basic architecture of a typical PON 
The complexity of ATM and the need for larger bandwidths beside the progress in the technology pushed the researcher to look for a better technology. Gigabit Passive Optical Network GPON standardization work was initiated in the year 2001 for designing networks over 1 Gbps. GPON architecture offers converged data and voice services at up to $2.5 \mathrm{Gbps}$. GPON enables transport of multiple services in their native formats, specifically TDM and data. In order to enable easy transition from BPON to GPON, many functions of BPON are reused for GPON. GPON uses the Generic Framing Procedure (GFP) protocol to provide support for both voice and data oriented services. A big advantage of GPON over other schemes is that interfaces to all the main services are provided and in GFP enabled networks packets belonging to different protocols can be transmitted in their native formats.

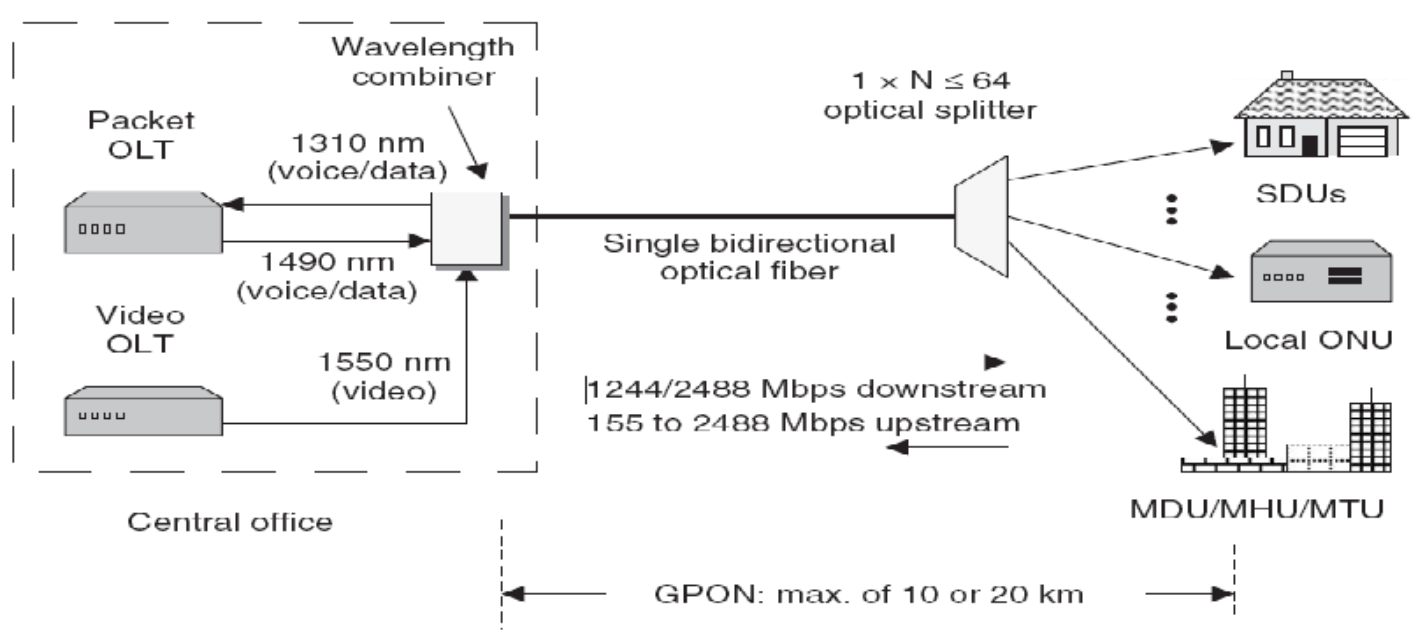

Fig. 2 General GPON architecture and characteristics

\section{2-c. 10GPON}

New technologies implementation from existing standards are needed to cope the applications and services such as HD IPTV, video-on-demand (VoD), voice over IP (VoIP), video conferencing, online gaming and peer-to-peer (P2P) networking. NGPON (Next Generation Passive Optical Networks) are very recent standards, even still in study and very expensive, so it will be applicable for future projects. 10GPON (XG-PON) is a broadband transmission standard represents the next generation that follows from GPON (Gigabit capable PON) and enables its coexistence with 
installed equipment of the same network. In addition, 10GPON can be an extension of current GPON and deployment could be reused.

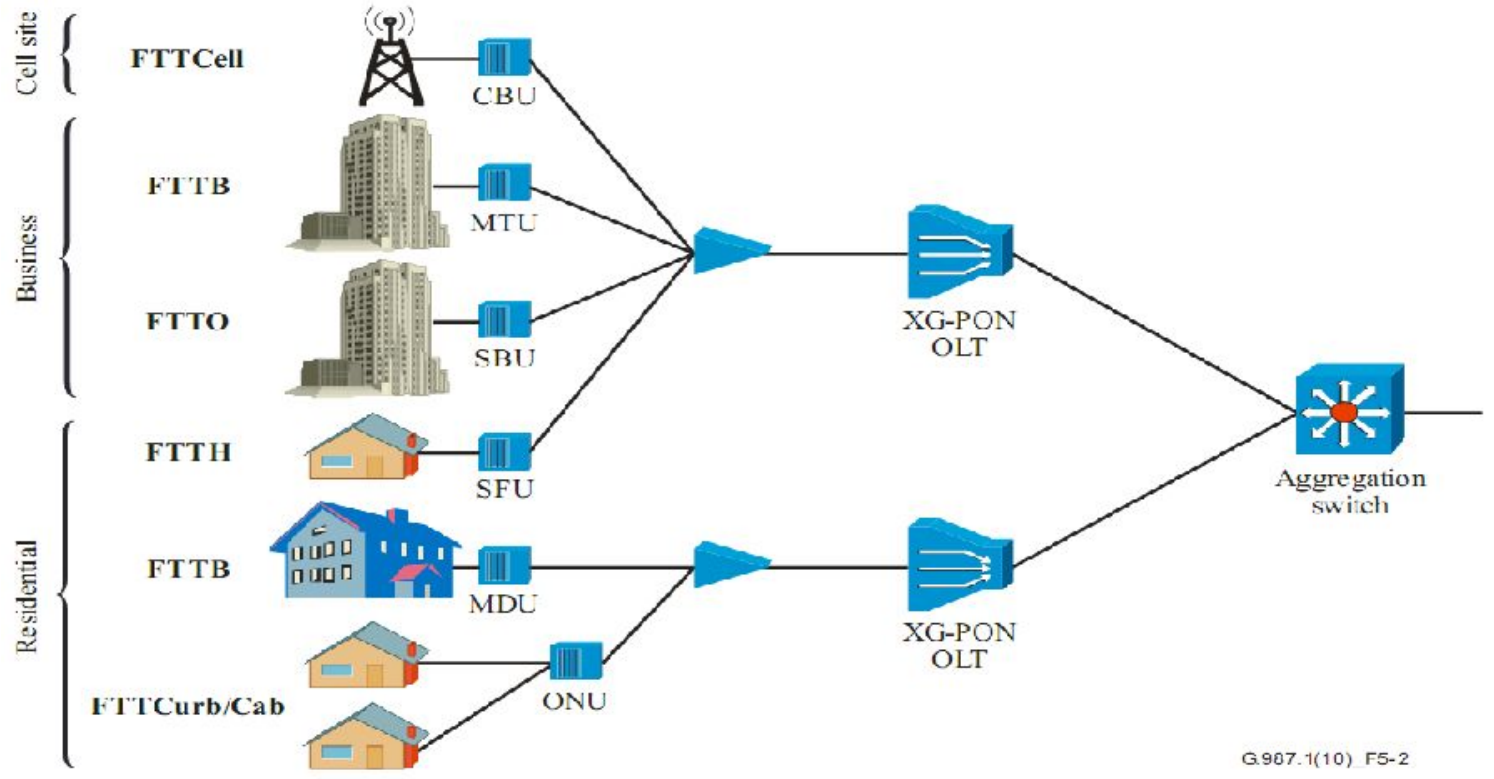

Fig.(3) XG-PON architecture scenarios. (Telecommunication Standardization Sector of ITU-T, 2010)

\section{PON Modeling:}

Figure 6. shows the block diagram of the proposed model. It consists of transmitter (Data generation combined with fiber optic signals), Splitter system which can be distributed into many users (32), the receiver which receive the signals and convert it into electrical form. The final stage of our system is the bit rate error analyzer where the sending signals and received ones can be compared. The bit error rate analyzer is the judge if our results indicating either the systems are good or not [38].

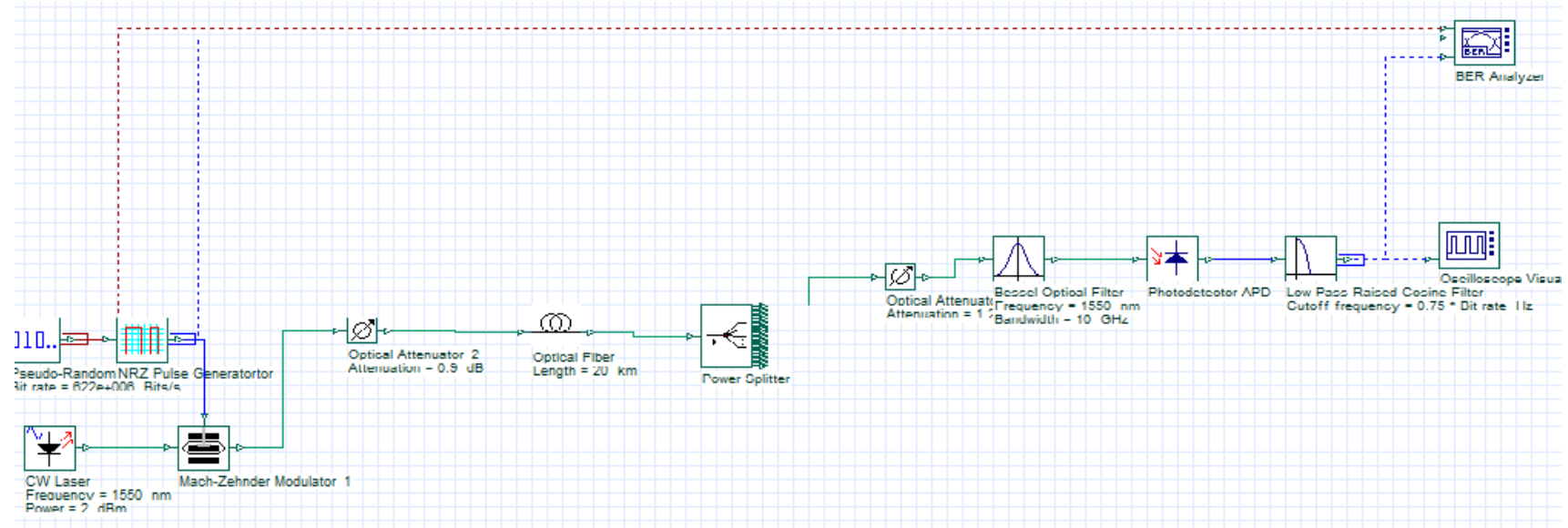


Fig. 6

Data/voice transmitter consist of $2.5 \mathrm{Gbps}$ pseudo random bit sequence (PRBS) generator, NRZ driver, CW externally modulated laser at $1490 \mathrm{~nm}$ wavelength, and Mach-Zehnder external modulator as shown in figure 4.

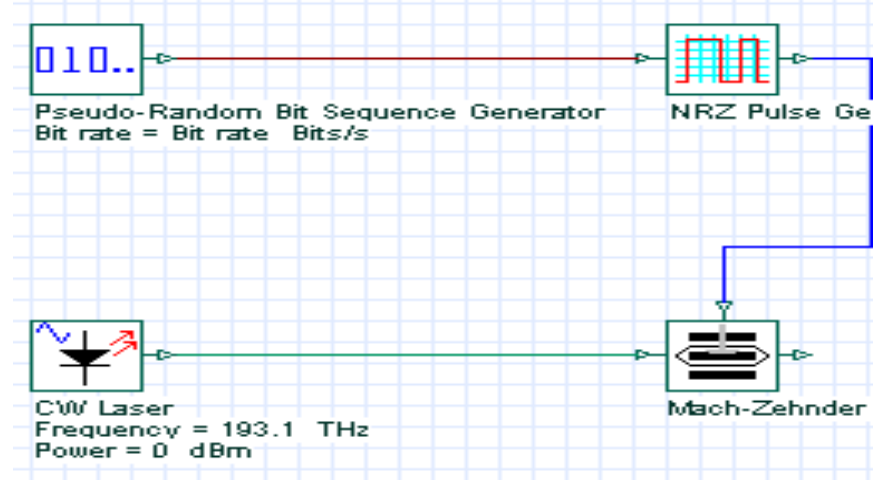

Fig. 4 OLT

Data receiver configured with Bessel optical filter, photo detector PIN receiver as shown in Figure 5.

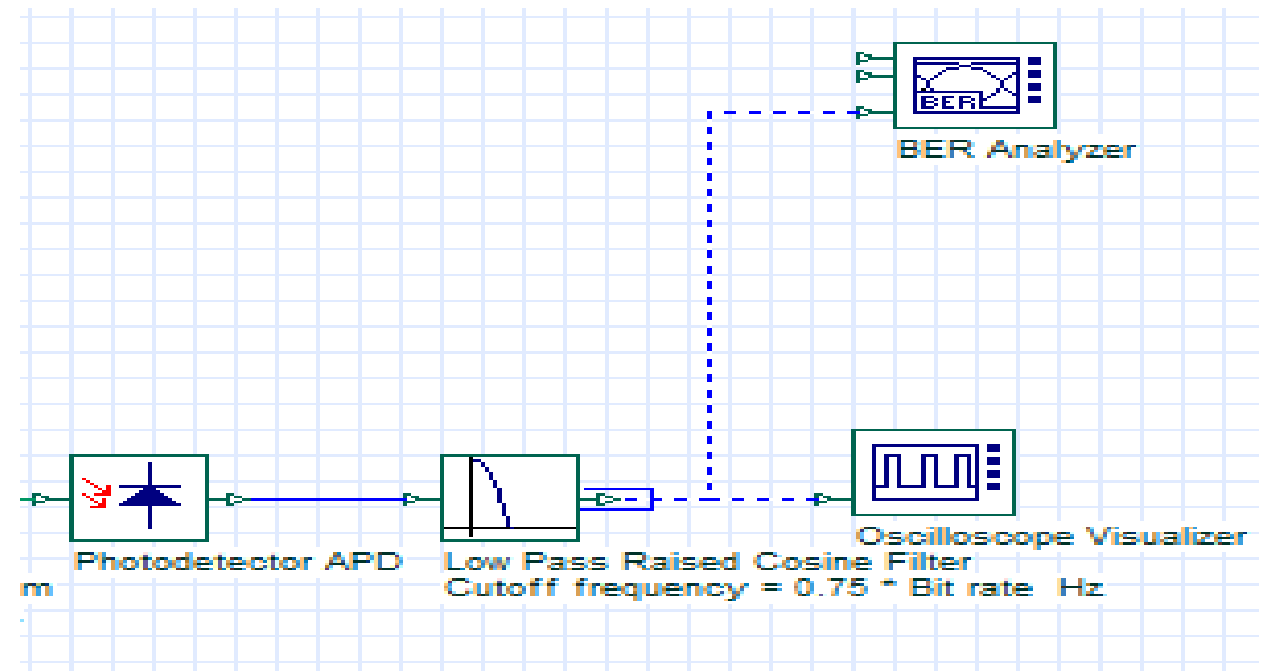

Fig. 5 ONU

\section{Model Result's Analysis:}

\section{a. BER vs Distance}

Figure 9 shows the relation between BER and length for different power levels for 32 users For GPON 32 users, it has found that the signal having $1 \mathrm{db}$ does not cross any 
distance while the signals having high power levels $2,3,4,5,6 \mathrm{db}$ will reach for 17 , $20,26,34,37 \mathrm{~km}$ respectively.

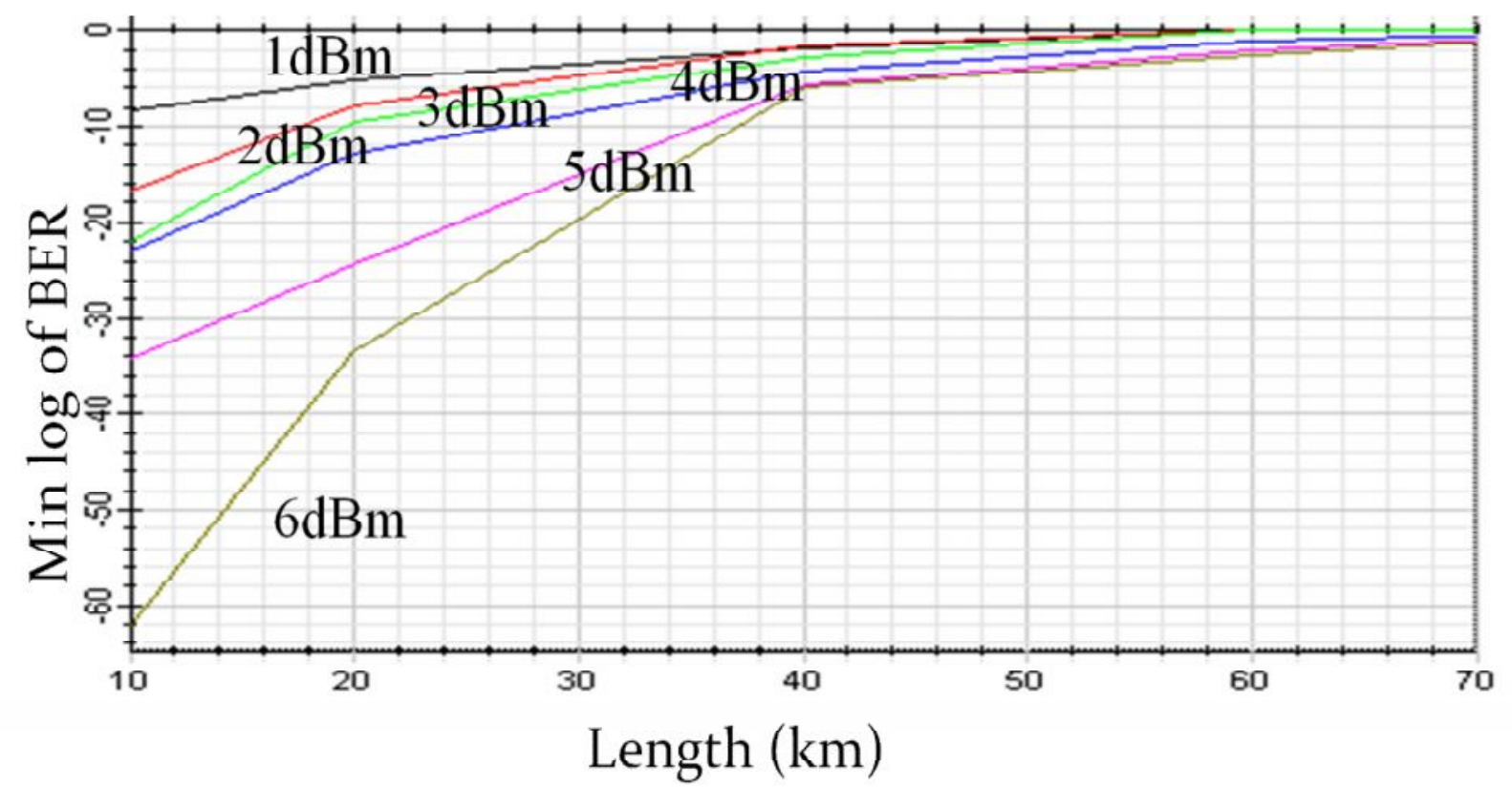

Fig(9). GPON 32 users (BER Vs. length)

In figure 10 the effect of the increasing the signals bit rates on the distance for different power levels and different number of users will be studied, while Figure 10 shows BER versus length for different power levels for 10-GPON 32 users the distance will be decreased to $14 \mathrm{~km}, 15 \mathrm{~km}, 19 \mathrm{~km}, 25 \mathrm{~km}, 27 \mathrm{~km}, 29 \mathrm{~km}$ at the same power levels from $(1-6 \mathrm{dBm})$.

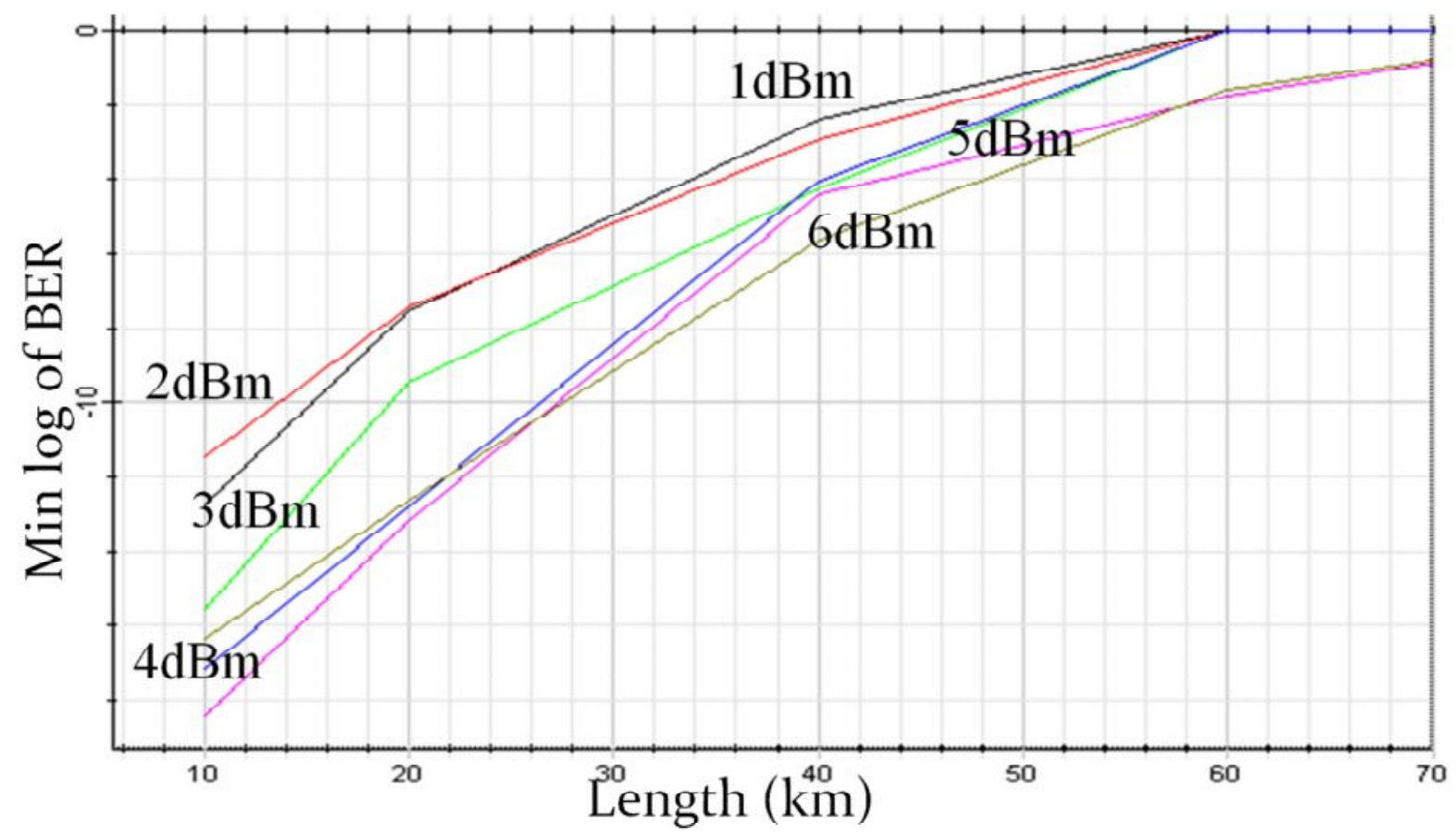


fig(10). 10-GPON 32 users (BER Vs. length)

\section{b. BER vs Power}

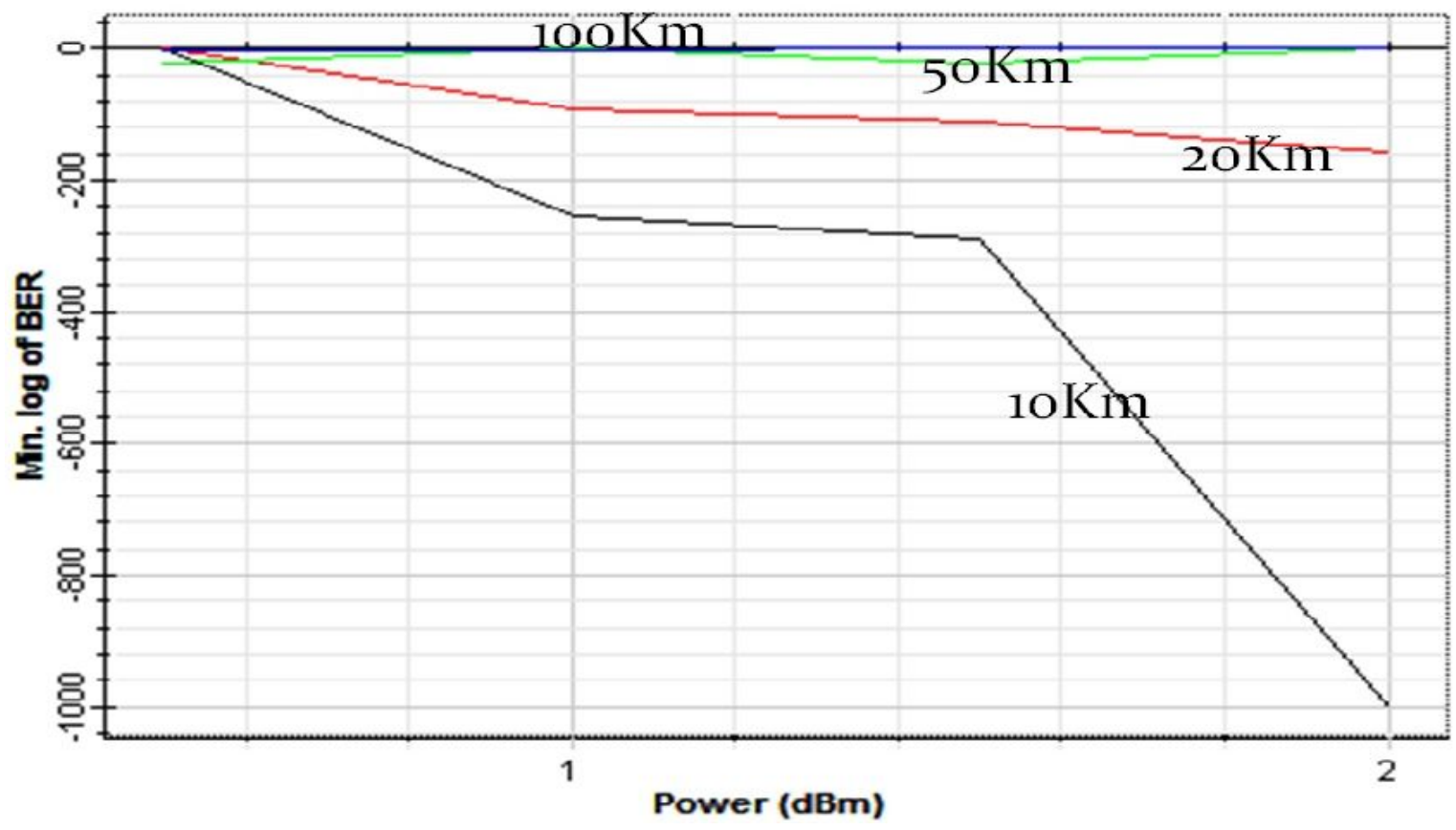

fig(11). BER Vs. power at PON bit rates \& 16 users

Figures 11 shows the relation between BER and power for different distances of 10, 20, 50, and $100 \mathrm{Km}$ for PON system with 16 users.

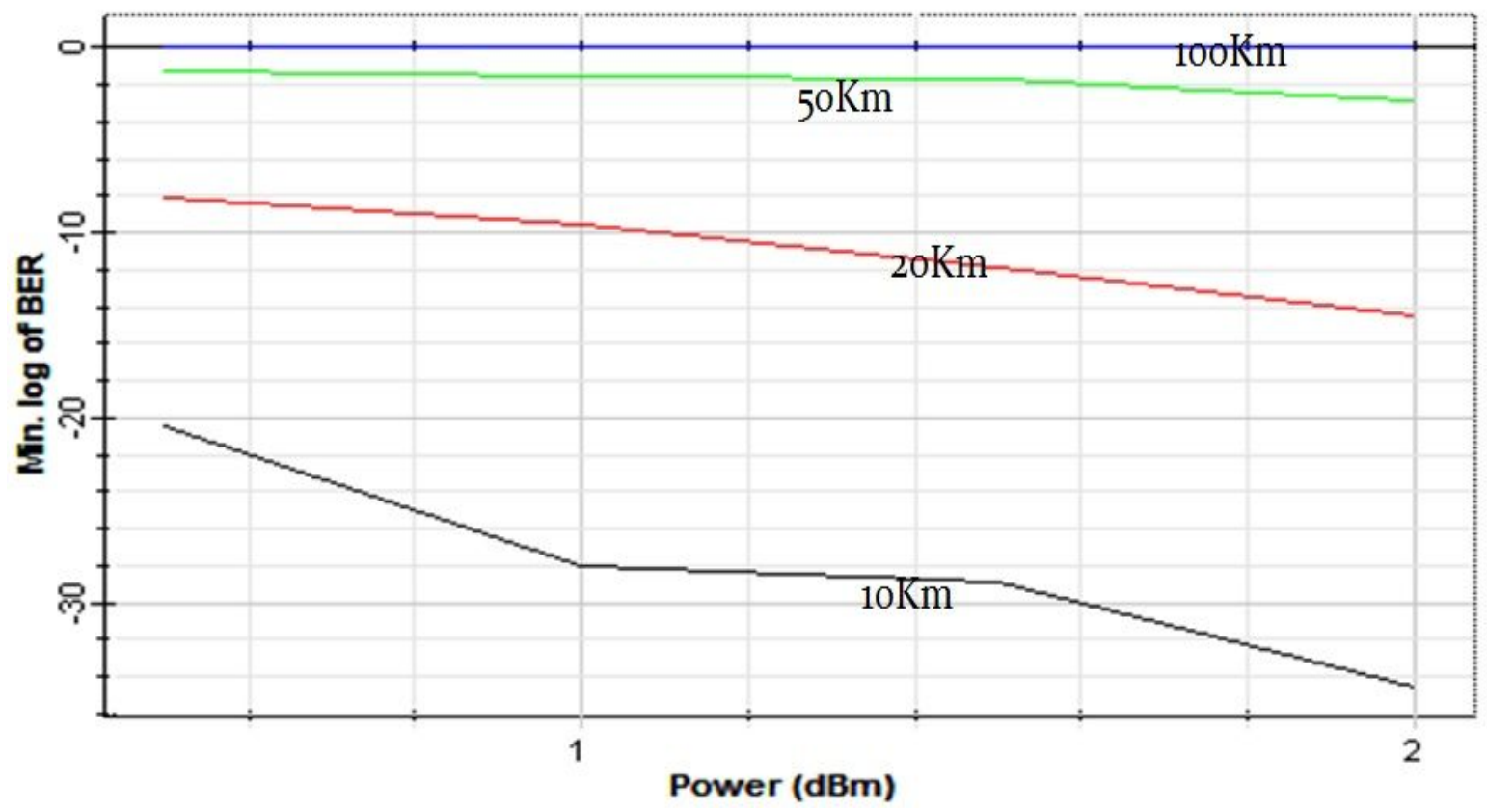

Fig(12). BER Vs. Power at GPON Bit Rates \& 32 Users

Figure 12 shows the relation between BER and power level for different distance for Gpon system with 32 users. It has found that at 32users, the signal will cross $10 \mathrm{~km}$ and $20 \mathrm{~km}$ at specific margin of power levels $(1 \mathrm{~dB}-2 \mathrm{~dB})$ at 32 users. 


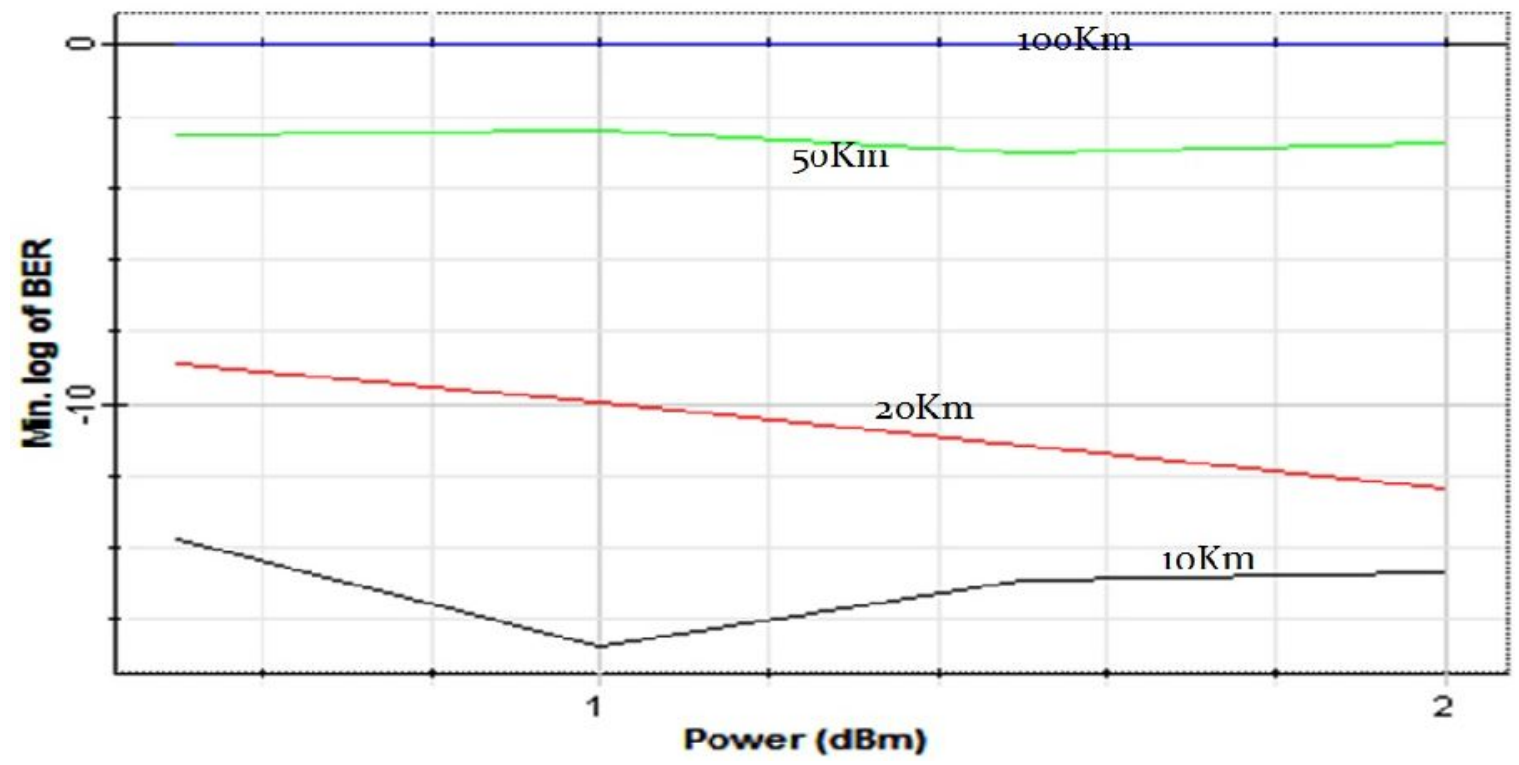

fig(13). BER Vs. power at 10-GPON bit rates \& 32 users

Figure 13 shows the relation between BER and power level for different distance for 10 GPON system with 32 users. By increasing the number of users reaching for 32 , it has been noted that the signals do not cross the $20 \mathrm{~km}$ till have certain limits of power .

\section{c. BER vs. Distance for different Bit Rate}

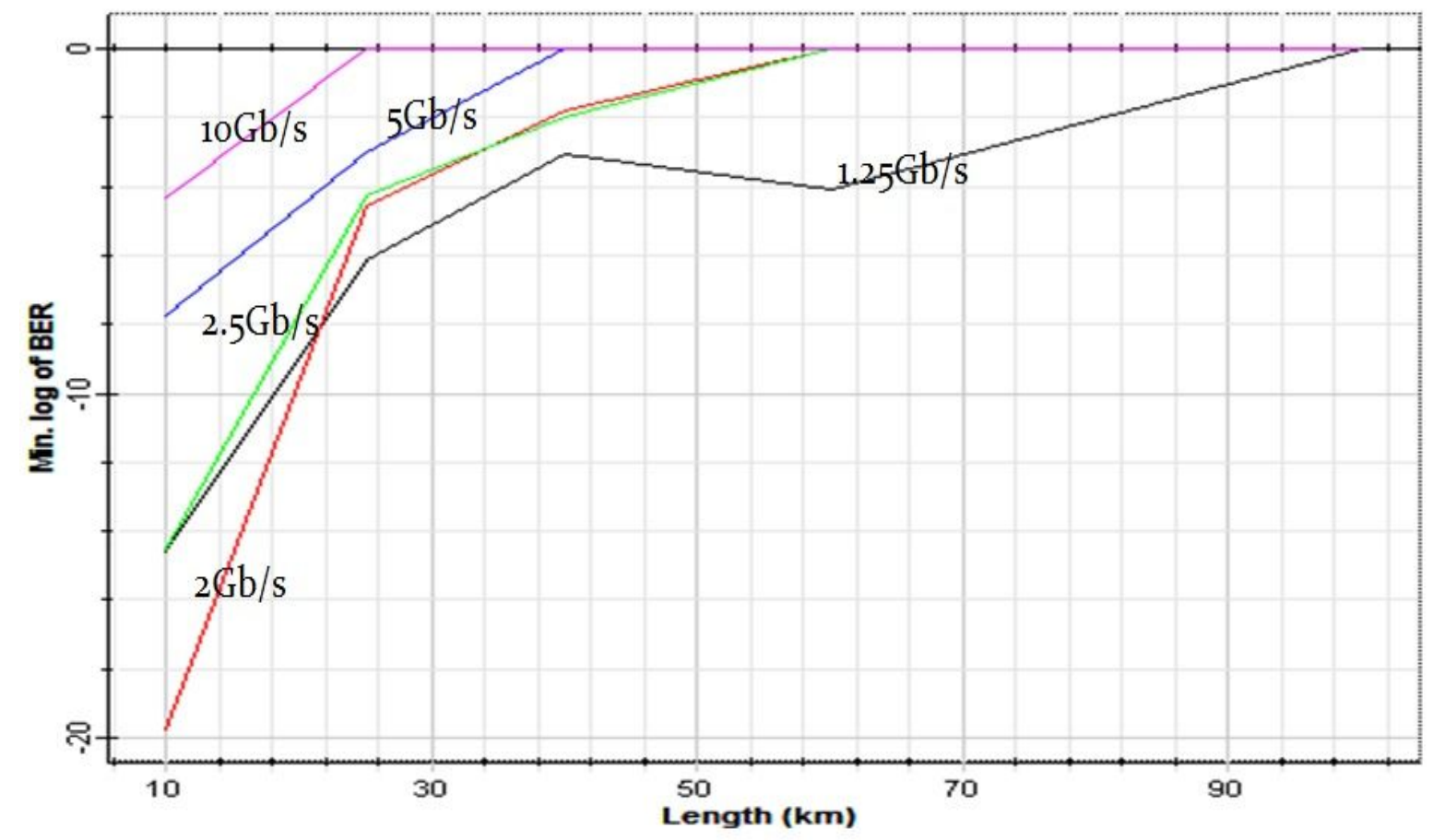


Fig.(14) BER VR length different Bit rate at 32 users

Figure 14 shows the relation between BER and distance level for different bit rate, the proposed system has been tested with the signal bit rates starting from $1.25 \mathrm{~Gb} / \mathrm{s}$ till $10 \mathrm{~Gb} / \mathrm{s}$. At 32 users, the signals with bit rates $1.25 \mathrm{~Gb} / \mathrm{s}, 2 \mathrm{~Gb} / \mathrm{s}, 2.5 \mathrm{~Gb} / \mathrm{s}, 5 \mathrm{~Gb} / \mathrm{s}$ and $10 \mathrm{~Gb} / \mathrm{s}$ will reach distances $20 \mathrm{~km}, 18 \mathrm{~km}, 16 \mathrm{~km}$ and the signals will be stopped and do not cross over.

\section{Conclusions:}

In this study, we have introduced some methods for comparing the used techniques as PONs, GPONs and XGPONs for data transmission. Our aim is to indicate the advantages and disadvantages of every method by using Opti-System simulating program. The comparison has been performed to the most important parameters to judge the used technique. The bit rate and the transmission distance are the most important parameters. Also in this paper, we aim to explain the design and planning of a PON which can build a fictitious environment allowing us to show FTTH networks in depth and decide which the most optimal solution for this environment is. We have established a network architecture based on FTTH systems with different data bit rates $(1.25 \mathrm{~GB} / \mathrm{s}, 2 \mathrm{~GB} / \mathrm{s}, 2.5 \mathrm{~Gb} / \mathrm{s}, 5 \mathrm{~Gb} / \mathrm{s}$ and $10 \mathrm{~GB} / \mathrm{s})$. This architecture is targeted to deliver a very high speed data using optical communication between the used systems. It is demonstrated that as by increasing the data rate, the number of accommodated users decreases due to high range bit error rate. Also by increasing the distance of transmission, the system will be undesirable due to increasing the bit error rate. And by increasing the number of users, the system will be unstable due to increasing the Bit Error Rate. On the other hand, it has noted that the Bit Error Rate decreases by increasing the power level.

\section{References:}

1. Monika Gupta1, Neeru Malhotra2 and A. N. Pathak. "Performance Analys: FTTH at $10 \mathrm{Gbit} / \mathrm{s}$ by GEPON Architecture". IJCSI International Journc Computer Science Issues, Vol. 7, Issue 5, September 2010. ISSN (Online): 1 0814

2. Rajneesh Kaler, R.S. Kaler, "Simulation of Fiber to the Home at $10 \mathrm{Gbit} / \mathrm{s}$ c GE-PON architecture”, Optik 122 (2011) 1362- 1366. 
3. Björn Skubic, Jiajia Chen, Jawwad Ahmed and Lena Wosinska, Biswء Mukherjee. " A Comparison of Dynamic Bandwidth Allocation for EPON, GF and Next-Generation TDM PON”. IEEE Communications Magazine •March 20

4. Marija D. Mraković and Petar S. Matavulj" Analysis of Coexisting GPON and PON1 (10G-PON) Systems”. Telfor Journal, Vol. 3, No. 1, 2011.

5. K. Maamoun, H. Hua, M. Savoie" Performance Characterization of Technologies" Broadband Applications and Optical Networks, communica Research Centre, Ottawa, 2006.

6. Guoliang Nan, Shaofeng Zhang, Yiwei Lin*, Guozhong Zhang. "Power Fiber tı Home Opens Up a New Approach of Integration of Three Networks" 12 (2 429-436.

7. Nitish Verma, Ankur Singhal. "Performance analysis of FTTH Gigabit Eth Passive Optical Network (GEPON) system with triple play services”, IJECT V، Issue 3, Sept. 2011, ISSN : 2230-7109(Online).

8. Sandeep Singh, Arvind Kumar Jaiswal, Mukesh Kumar. "Transmission of V, Video and Data in Fiber-To-The-Home (FTTH) Networks Using OF] International Journal of Advanced Research in Computer Science and Soft Engineering Volume 2, Issue 5, May 2012, ISSN: 2277 128X .

9. Keiser, Gerd “FTTX concepts and applications". John Wiley \& Sons, Inc. $200 €$

10.Rajiv Ramaswami, Kumar Sivarajan and Galen Sasaki, (2009-07-16), "Or Networks - A practical perspective", Third Edition, ISBN: 978-0-12-3740 (C)2010 Elsevier Publication.

11.Ivica Cale, Aida Salihovic, Matija Ivekovic. “ Gigabit Passive Optical Netr GPON Universidad Tecnica de Lisboa”. On September 11, 2009 from IEEE Xp

12.ITU-T, Rec. G.983.1. Study group 15, "Broadband optical access systems base Passive Optical Networks (PON) ": general characteristics. ITU-T, Rec. G.983. 
2005).

13.ITU-T, Rec. G.984.1. Study group 15, "Gigabit-Capable Passive Optical Netw (GPON) ": general characteristics. ITU-T, Rec. G.984.1, March 2008

14.ITU-T G.984.3“ Gigabit-capable Passive Optical Networks (GPON) Transmission convergence layer specification, 02/2004.

15.C. Lee, W. V. Sorin, and B. Y. Kim, "Fiber to the home using a ] infrastructure", IEEE J. Lightwave Technol., vol. 24, no. 12, pp. 4568-4583, 2006. 